DOI: 10.22374/jmhan.v4i1.39

\title{
HARM REDUCTION: A CONCEPT ANALYSIS
}

Amie Kerber, RN, BScN; Tam Truong Donnelly, RN, BScN, MScN, PhD; Aniela dela Cruz, RN, MSc, PhD

Amie Kerber is a Master of Nursing Student, Faculty of Nursing, University of Calgary.

Tam Truong Donnelly is a Full Professor, Faculty of Nursing, University of Calgary.

Aniela dela Cruz is an Assistant Professor, Faculty of Nursing, University of Calgary.

Corresponding author: amie.kerber1@ucalgary.ca

\begin{abstract}
\section{Background}

Over the last 25 years, harm reduction has shifted to focus on public health and addressing the opioid crisis. Nurses working in addictions treatment utilize the principles of harm reduction to improve the health of clients.
\end{abstract}

\section{Aims}

Concept clarity assists healthcare providers to understand the applications and attributes of a concept.

\section{Method}

A concept analysis of harm reduction using the Rodgers (1989) method of evolutionary analysis was undertaken. A comprehensive review of the literature was conducted using CINAHL Plus and Social Work Abstracts.

\section{Findings}

The key attributes of harm reduction include safety, supplies, education, partnerships, and policy. Applications of harm reduction include needle exchange programs, supervised consumption sites, medication-assisted treatment, and increased access to take-home naloxone kits. The main antecedent to harm reduction is the presence of harm. Consequences explored include safer injection practices, decreased transmission of blood-borne illnesses, improved client relationships, and decreased overdose-related deaths. Stigma, health promotion, and pragmatism are the related concepts discussed. A model case is provided.

\section{Conclusion}

The principles of harm reduction are becoming increasingly popular as an inclusive and evidence-based nursing approach to addictions treatment and management. As using substances continues to shift and increase, harm reduction strategies must remain malleable and available in both the community and hospital settings to address the issue and decrease the associated healthcare costs. Future implications for nursing practice and research are provided. 
The context for the concept analysis lies within the growing concern of substance use-related deaths in Canada in recent years, particularly with opioid use. Public health officials have declared an opioid crisis in regions across Canada. ${ }^{1}$ Between January 2016 and June 2018 more than 9000 Canadians lost their lives due to opioid use. ${ }^{1}$ The Canadian Institute for Health Information $^{2}$ reports that hospitalizations related to opioid poisoning have increased $27 \%$ over the last five years. It is estimated that in Canada the cost of substance use on society has reached a staggering high of 38.4 billion dollars per year. ${ }^{3}$ Harm reduction "is an essential evidence-based approach for reducing the adverse health, social and economic consequences of substance use without requiring abstinence.." ${ }^{4}$ Clients across all spectrums of nursing care can be impacted by substance use and addictions.

Concept analysis is defined as a method of examining, clarifying, and defining unclear concepts. ${ }^{7}$ The result of concept analysis can lead to further evaluation of a concepts strengths and limitations, as well as encourage more effective and clear usage of the concepts that are analyzed.$^{7}$ Nurses often spend the most time with clients in the Canadian healthcare system, ${ }^{6}$ and work in a variety of areas including emergency rooms, urgent care facilities, medication-assisted treatment models, and detox facilities. Therefore, clarity of harm reduction concept can assist nurses with knowledge dissemination, organization of healthcare, team communication, clarity of treatment goals, and increased awareness of the unique phenomena experienced by patients. $^{7}$

In this paper, we present an evolutionary analysis of harm reduction using the Rodgers method of concept analysis. ${ }^{7}$ Thorough review of the literature identified five key attributes for the concept of harm reduction. These essential attributes include safety, education, supplies, partnership, and policies. To gain a better understanding of the concept of harm reduction, we briefly summarize its principles and philosophy. We will also discuss future implications for nursing practice and research.

\section{PRINCIPLES AND PHILOSOPHY}

The Canadian Nurses Association ${ }^{4}$ describes harm reduction as a pragmatic public health approach "for reducing the adverse health, social and economic consequences of substance use." The principles of harm reduction have been practiced in communities of varying cultures since the use of psychoactive substances began. ${ }^{5}$ Some examples of early utilization include providing opium to citizens registered as "addicts" in Europe and Asia in the $18^{\text {th }}$ and $19^{\text {th }}$ centuries, and education disseminated in "underground magazines" in the 1960s to encourage safer substance use. ${ }^{5}$ Over the last 25 years, harm reduction principles have been more deeply rooted within public health policy to decrease the transmission of bloodborne illnesses. ${ }^{5}$ With the opioid crisis emerging in North America, harm reduction principles have expanded to include policies and programs to decrease deaths from opioid poisoning. ${ }^{4,8}$

The theoretical foundation of harm reduction is a critical social theory. Critical social theory can be used to examine how social hierarchy and power promote "othering" of people who use opioids. ${ }^{9}$ Treatment avoidance decreased rapport, and communication breakdown negatively affects healthcare provision when attitudes of healthcare professionals are interpreted as stigmatizing by people who use opioids. ${ }^{10}$ Harm reduction seeks to challenge these attitudes and to encourage healthcare practitioners to engage in open communication with clients regardless of their substance use. ${ }^{4}$

Critical social theory is a philosophical approach that addresses how societies or communities are oppressive, unjust, influenced by relationships between knowledge and power, and how these dynamics serve to maintain the status quo. ${ }^{11}$ Critical theory is a useful lens to view health and social care because a hierarchy of power applies to many relationships within the healthcare system. ${ }^{9}$ Nurses are observed to be in a position of power when interacting with clients, and with this power, they can determine what the appropriate outcomes might be for clients who use opioids (such as the goal of abstinence from substances). When a critical social theory is used to guide nursing practice within the concept of harm reduction, power dynamics can shift, and for the client to feel empowered to make informed lifestyle choices, while still being supported by healthcare staff.

J Mental Health Addic Nurs Vol 4(1):e14-e25; May 18, 2020.

This article is distributed under the terms of the Creative Commons Attribution-Non Commercial 4.0 International License. (C) Kerber et al. 
We believe the principles of harm reduction are in line with moving people towards empowerment and emancipation from unequal social relationships and power struggles to improve equality in healthcare and decrease stigma. Examining harm reduction through the philosophy of critical social theory can assist healthcare professionals in addressing many issues related to social dynamics created by power differentials. For example, people might believe that harm reduction principles encourage drug use. Substance use is believed by some to be a moral failing, which reinforces the stigma and shame experienced by the person using substances. ${ }^{12}$ When we look at substance use as a naturally occurring phenomenon, we might view harm reduction as a means to promote safer practices for people requiring extra support. ${ }^{4}$

Nurses adopting a critical social theory philosophical framework can examine how health disparities and healthcare inequities exist at the community, healthcare, and policy levels to challenge the status quo and improve harm reduction utilization. ${ }^{13}$ Utilizing this philosophical approach, nurses have the opportunity to create meaningful and authentic relationships with clients who may previously have poor outcomes when accessing healthcare services. Nurses are in a position to implement, research, review, and educate on the concept of harm reduction, which helps to reduce the harms of illicit drug use for their clients. ${ }^{14}$

Rodgers ${ }^{7}$ describes concepts as fluid and subject to change based on how the concept is being expressed in society. Rodgers ${ }^{7}$ proposed a 7-step, non-linear method which was selected for this evolutionary analysis of harm reduction. See Figure 1 for a diagram of the Rodgers framework. We explore how harm reduction has been conceptualized and utilized in the health and social sciences, primarily in Canada, but also utilizing research from the United States and the United Kingdom. Canada continues to be one of the leading countries implementing harm reduction programs in the spectrum of addiction care. As such, we will focus on the implications of a harm reduction approach within the Canadian healthcare context.

\section{HARM REDUCTION: A CONCEPT ANALYSIS REVIEW OF LITERATURE}

Harm reduction has a robust database of evidence that reinforces its importance as a pillar of substance abuse policy. ${ }^{8,14,15}$ Cumulative Index to Nursing \& Allied Health Literature (CINAHL) Plus and Social Work

FIG. 1 Rodgers framework. ${ }^{7}$

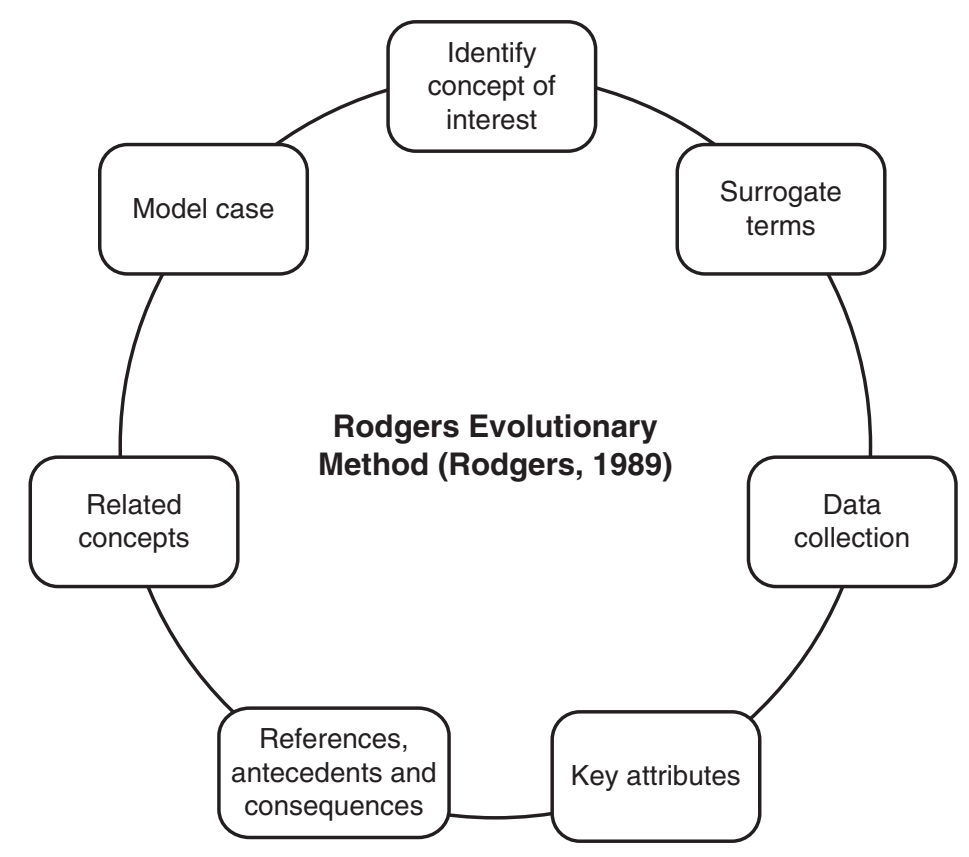

J Mental Health Addic Nurs Vol 4(1):e14-e25; May 18, 2020.

This article is distributed under the terms of the Creative Commons Attribution-Non

Commercial 4.0 International License. (C) Kerber et al. 
FIG. 2 Literature search flowchart.

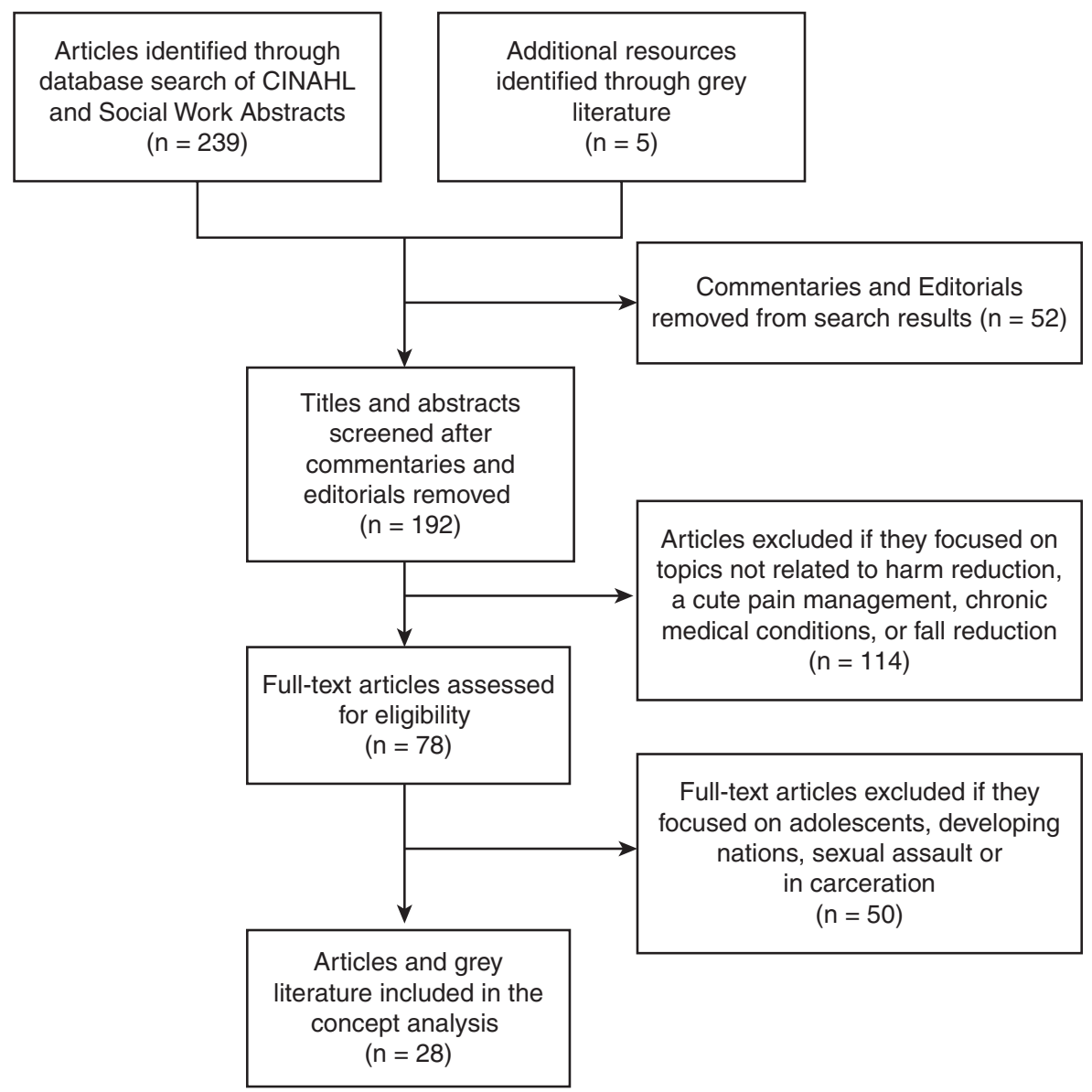

Abstracts were the databases used for the collection of articles due to their extensive literature base. The main search term used was "harm reduction." Other search terms combined with harm reduction included "Canada." "needle exchange programs," "opioid addiction," "opioid," "naloxone," "nursing," "harm," and "addiction." Inclusion criteria included peer-reviewed articles, full-text availability, English language, abstract, and reference availability. Articles were narrowed down to the time frame of 2006-2019 as this is when harm reduction policy began to be more extensively researched. The initial search yielded 239 articles. Commentaries and editorials were not included. The disciplines of nursing, social work, pharmacy, and physicians were focused on due to their intersectoral collaboration in the healthcare provision to those who have addictions. Grey literature from the Canadian
Government, Canadian Nurses Association (CNA), BC Centre on Substance Use (BCCSU), and the Canadian Centre on Substance Abuse and Addiction was also utilized in data collection. Through these criteria 24 scholarly articles, one nursing position statement, and three government websites were reviewed to gain a better understanding of harm reduction. See Figure 2 for the complete literature search flowchart.

\section{FINDINGS}

\section{Surrogate Terms}

Rodgers $^{7}$ encourages the identification of surrogate terms during concept analysis as it is common for several terms to be used interchangeably. Therefore, to provide conceptual clarity it is important during concept analysis to identify related terms that are used 
to indicate the concept. This ensures the linguistic manner of the terms used to describe a concept is consistent. ${ }^{7}$ The term "harm reduction" was consistently used throughout the literature. However, two of the reviewed articles identified "harm minimization" as a common reference. ${ }^{5,16}$ Ball $^{5}$ also identified "risk reduction" and "vulnerability reduction" as "terms used to convey harm reduction principles in situations where the term harm reduction is taboo." McKeganey ${ }^{17}$ used the term "reducing drug users' risk behavior" in place of harm reduction. As harm reduction extends beyond reducing the risk of harm to substance users, such as through condom distribution, or the use of nicotine replacement therapy ${ }^{4}$ it is important to be clear that this concept has more applications and not associate it strictly to substance use harm.

\section{Key Attributes}

Clarity of concept attributes leads to increased communication and cognitive recall for people when the phenomena of a concept might not be immediately present. ${ }^{7}$ Five key attributes were identified through a review of the literature. These attributes are inclusive of all applications of harm reduction. They are safety, supplies, education, partnerships, and policy. To be effective at improving clients' outcomes, we believe these attributes should be present in all harm reduction programs and services.

\section{Safety}

One of the key attributes of harm reduction is creating safety for clients who are at risk of harm. Physical safety is experienced through the opportunity to use substances without the fear of overdosing, through knowing the supplies being used are new and "clean," or carrying a take-home naloxone kit so that if someone overdoses it can be reversed. ${ }^{18-221}$ Psychological safety encompasses a non-judgmental attitude by healthcare providers that aims to prevent death while supporting safer use of substances. ${ }^{4}$ Feeling emotionally safe can improve the therapeutic relationship between the client and the healthcare provider. Thus, it increases client utilization of services and the likelihood of continued engagement in harm reduction programs or healthcare follow up. ${ }^{22,23}$ Another aspect of safety to consider is the choice of continuing to use substances. Nurses can educate clients on risks of overdose, such as using opioids and benzodiazepines concurrently, ${ }^{3}$ importance of not using substances alone, ${ }^{6}$ and if clients chose to stop using substances, agencies that can assist clients to safely detox.

\section{Education}

Client education is an important aspect of harm reduction practices to ensure clients are aware of how to reduce harm in various situations. Bowles and Lankenau ${ }^{19}$ created an education program focused on educating clients on the signs and symptoms of overdose, activating emergency response, and administering naloxone. This program was first facilitated by the healthcare team at a harm reduction facility in Philadelphia, USA. It aimed to dispel myths about how to stop overdoses (such as splashing cold water on someone or injecting them with salt), and to teach people how to use naloxone kits. By disseminating knowledge to people who use substances, the information is more likely to be passed along through "hidden social networks" (for example, people who do not use the facility). ${ }^{19}$ Education within supervised consumption sites, such as Insite in Vancouver, Canada, has also focused on client-specific health concerns, and proper injection or substance use techniques to minimize risks such as infection or abscess. ${ }^{6,24}$

\section{Supplies}

The provision of supplies is one of the most wellknown attributes of harm reduction. Supplies can include syringes, cookers, sterile water, condoms, pipes, take-home naloxone kits, and sharps containers. ${ }^{6,14,21,25}$ However, Wallace, Barber, and Pauly ${ }^{26}$ states "harm reduction is incomplete when harm reduction mandates are perceived as the distribution of supplies, in the absence of harm reduction philosophy." Wallace et al. ${ }^{26}$ described how various shelters in Vancouver, Canada would offer sterile supplies but prohibit the use of substances on-site. This partial implementation of harm reduction "contributes to a microenvironment in which harm has the potential to be increased when residents do not feel safe to access supplies and fear repercussions or punishment for use. This environment also increases the risk of concealed or hidden use." ${ }^{26}$ While access to supplies is important, it cannot be at the cost of the philosophy of harm reduction which emphasizes the relational aspects of human

J Mental Health Addic Nurs Vol 4(1):e14-e25; May 18, 2020.

This article is distributed under the terms of the Creative Commons Attribution-Non

Commercial 4.0 International License. (C) Kerber et al. 
relationships, the experience of the individual, and a nonjudgmental approach.

\section{Partnership}

We believe partnership in harm reduction occurs at the macro and the micro-levels. At the micro-level, partnerships are formed between clients and staff such as nurses, peer support workers, socials workers, or physicians. Examples of effective partnership result in increased access to primary healthcare services for those who use supervised consumption sites ${ }^{18,25}$ and through medication assistance treatment models that provide methadone and suboxone to opioid users. ${ }^{27}$

Health and social care providers in harm reductionbased programs are often the first points of contact for people who use substances and connect their clients to several healthcare services such as substance use treatment programs, medication-assisted treatment programs, and social services. ${ }^{22,23}$ The basis of creating community-based partnerships begins with partnerships between clients and harm reduction program staff. People using harm reduction programs have often experienced stigma when accessing medical services in the past. ${ }^{28}$ When nurses working in harm reduction programs build therapeutic relationships with their clients they improve the trust and willingness of clients to access external community resources. For example, clients may be referred to medicationassisted treatment programs. Mattick et al ${ }^{29}$ found that methadone was more effective in keeping opioid users in treatment programs than non-opioid therapies. By maintaining strong partnerships between community organizations, clients using this program have greater access to other healthcare services through increased referrals and improved overall wellness.

\section{Policies}

Policies are an example of how partnerships are present at the macro level. The Canadian federal government is working with provincial and territorial governments to increase harm reduction programs such as supervised consumption sites and access to take-home naloxone kits. ${ }^{8,30,31}$ An example of a shift in Canadian policy to support harm reduction can be seen in the Good Samaritan Drug Overdose Act. ${ }^{32}$ This exemption was passed in Canada in 2017 to protect people seeking emergency treatment for overdoses, or people who initiate an emergency response, from charges of possession of a controlled substance or breach of conditions regarding simple possession of controlled substances. ${ }^{32}$ Further research on harm reduction through the Canadian Research Initiative in Substance Misuse (CRISM) is also being conducted to encourage communication and collaboration across addiction service providers, researchers, policy-makers, and people who use substances. ${ }^{33}$ The Canadian Nurses Association ${ }^{4}$ stresses that "policies and programs must be based on best evidence, cost-effectiveness, and local needs - all while involving the participation of those who use substances in decisions that affect them." Nurses should be astute at identifying and advocating for change to harmful policies that reduce access to health and social services, violate human rights, and are not based in the principles of harm reduction. ${ }^{4}$

\section{Applications}

References for application of a concept helps clarify how the concept is appropriately experienced (or operationalized) in a range of situations and events to differentiate what is, and what is not, an application of the concept. ${ }^{7}$ The most commonly known application of harm reduction for people who use substances is needle exchange programs. ${ }^{5,14,18}$ Recently supervised consumption sites ${ }^{6,25,34}$ and take-home naloxone kits ${ }^{19,21}$ have increased in availability in Canada. Also, housing-first policies and homeless shelters employ harm reduction strategies and offer basic needs such as shelter, hygiene supplies, nicotine replacement therapy and food. ${ }^{26,34,35}$

\section{Antecedents}

Antecedents are the phenomena or conditions that precede the concept occurrence. ${ }^{7}$ Harm reduction is intended to reduce the harms of various behaviors without the goal of abstaining from the behaviour. ${ }^{4}$ The main antecedent to harm reduction is the presence of harm. "Harm occurs at different levels (individual, family, community, society) and in different forms (health, economic, social) and its measurement is often value-laden and determined by cultural norms and beliefs." 5

In the context of substance use, harm at the individual level would include adverse childhood experiences and living in poverty. ${ }^{15,20}$ Youth, First 
Nations individuals, LGBTQ+ (lesbian, gay, bisexual, transgender, queer, and others), women, and people with lower socioeconomic status and lower levels of education are at an increased risk of vulnerability and exposure to harm. ${ }^{5,20,34}$ At the community and societal level, the risk of being exposed to harm increases due to engagement with poor support systems, unsupportive or restrictive social programs, and unstable housing, or staying in shelters. ${ }^{26,34}$ It has been recognized that the use of opioids can occur due to chronic pain, stress, grief, loss, trauma. ${ }^{26}$

\section{Consequences}

Consequences, as defined by Rodgers ${ }^{7}$, are the outcomes of a concept occurring. The effectiveness of various strategies of harm reduction has been extensively researched and well established. Harm reduction creates safer environments and improves the health and quality of life of people who use substances, decreases mortality by preventing opioid overdoses, and increases positive relationships between healthcare providers and clients. ${ }^{15,21,34}$

At the individual level, Kerr et al. ${ }^{24}$ demonstrated that syringe exchange programs have decreased syringe borrowing practice among substance users from $20.1 \%$ in 1998 to $9.2 \%$ in 2003 . Safer injection practices reduce transmission of hepatitis $\mathrm{C}(\mathrm{HCV})$ and human immunodeficiency virus (HIV). ${ }^{20,34,36}$ This has a positive effect on the individual and societal level. Supervised consumption sites are expanding in their availability across Canada. Research has demonstrated that these sites decrease overdose deaths, increase connections with the healthcare system, and reduce risk behaviours..$^{25}$ Education on proper injection technique has been shown to decrease injection-related injuries such as abscess and cellulitis. ${ }^{6,25}$ Medication-assisted treatment models have been increasing in popularity as a harm reduction treatment approach since the 1960s. ${ }^{37,38}$ These programs also show a "reduction in the severity of the addiction, criminality levels, and street acquired heroin use, social adjustment improvement, cost-effectiveness, and so on." ${ }^{\text {37 }}$ Many of the programs that are in place at the individual level have a greater community and societal impact due to cost savings decreased level of criminal activity, and increased access to healthcare support. ${ }^{6}$

\section{Related Concepts}

Related concepts have a relationship to the concept being explored, but do not share the same defining attributes. ${ }^{7}$ Stigma had an overarching correlation with harm reduction, as those who are using substances are marginalized or experience stigma regularly. ${ }^{15,19,20,16,37}$ "The stigma of drug addiction is associated with negative perceptions and can be a barrier to treatment." 28

Health promotion was an underlying related concept expressed in the literature. ${ }^{5,18,31}$ The Living in Good Health Together (LIGHT) Project ${ }^{18}$ is an excellent example of harm reduction and health promotion working simultaneously alongside each other. The LIGHT Project was created as a needle exchange project in West Virginia, USA, in 2015, but has since expanded to provide health promotion initiatives including treatment referrals, family planning, Hepatitis C screening, and treatment, wound care, and access to primary care services. ${ }^{18}$

Pragmatism is defined as "a practical approach to problems and affairs." ${ }^{39}$ Harm reduction is described as pragmatic ${ }^{5,19,36}$ because it is a practical approach that recognizes that substance use is an "enduring feature of human existence." ${ }^{4}$ While being pragmatic in harm reduction is important, it is also necessary to be a visionary, to continue to expand the practical and philosophical approaches of harm reduction as they shift based on client needs.

\section{MODEL CASE}

A model case provides an everyday example that includes the attributes of the concept to assist in concept clarification ${ }^{7}$. The model case presented in this paper involves fictional characters, however, the circumstances and location are based on a clinic that is currently operational. Injectable opiate agonist treatment (iOAT) is an emerging second-line treatment for people who use opioids who are resistant to other forms of medication-assisted treatment such as methadone or suboxone. ${ }^{40}$ "Patients may not benefit from first-line medications for a variety of reasons, including cravings persisting despite optimal OAT [oral agonist treatment] dosing; patients being unable to reach a therapeutic dose; or opting not to initiate OAT (e.g., previous experience with OAT including side effects, intolerance, or insufficient reduction in 
craving and illegal drug use). ${ }^{\circ 1}$ iOAT provides people who use opioids with prescribed opioid medication (hydromorphone or diacetylmorphine) to inject in a safe and monitored clinic setting up to three times a day. ${ }^{42}$

The concept of harm reduction is balanced with a treatment approach to ensure the care being provided focuses on the patient's goals while encouraging them to move towards a more stable and healthier lifestyle. Evidence shows that people who attend iOAT clinics have a greater reduction in street heroin use compared to those who are treatment-resistant and on methadone treatment alone. ${ }^{43}$ "Outcome measures from treatment included improvements in physical and mental health, quality of life, family and social functioning, and reduction in the use of drugs other than heroin or opioids and crime. ${ }^{43}$ An example of a model case is as follows.

Lucy is a nurse that works at a new injectable opioid clinic in her city. The clinic provides prescribed hydromorphone to clients who have severe opioid use disorder. The clinic employs a multidisciplinary approach where healthcare is provided by a team of nurses, physicians, nurse practitioners, social workers, and peer support workers. The clinic was created after a sharp increase in deaths related to opioid poisonings occurred in the province. A harm reduction task force was formed to create policies and initiatives to help address the opioid crisis. Jacob is a client at the clinic. He comes to the clinic three times a day to receive his medication. Jacob is grateful to be a part of this treatment program as he feels it is safer to use hydromorphone instead of street purchased narcotics. Jacob has expressed appreciation to the staff for the emotional support they provide. He has an ulcer on his foot that is dressed daily and monitored by the nurse practitioners. He meets with the physician regularly to discuss his dose and substance use. During Jacob's second dose of the day, Lucy completes his wound care. Jacob asks Lucy for a Narcan kit as he had to use one this morning when he saw someone overdose on the steps of the church adjacent to the clinic building. Lucy spends time debriefing with Jacob about this experience after he receives his medication, and provides him with a new take-home naloxone kit.
This model case demonstrates all key attributes of the concept of harm reduction. The clinic provides a safe space for people who inject opioids to come and receive a prescribed medication instead of using fentanyl purchased on the street. Supplies are administered including prescribed medications, injection supplies, and take-home naloxone kits. Education is provided on safe injection techniques, as well as other healthcare issues based on the client's needs. Partnerships are one of the key aspects of the clinic as clients access care up to three times a day. Staff, including registered nurses, peer support workers, and social workers build trusting and therapeutic relationships with clients who may not have other support systems. The clinic was created out of an identified gap in policy and programs. It uses evidence-based research from Europe to help pave the way for a new treatment model within Canada. ${ }^{41,43}$

\section{FUTURE IMPLICATIONS FOR NURSING PRACTICE AND RESEARCH}

"The cost of hospitalizing people with substance use disorders (SUDs) increased 22\% over five years to \$267 million in 2011 from \$219 million in 2006."3 As substance use trends continue to shift, harm reduction strategies must remain malleable and available in both the community and hospital settings to decrease the costs associated with using substances. Evidence has shown that the implementation of harm reduction programs has led to positive outcomes including the decreased transmission of bloodborne illnesses,${ }^{24} \mathrm{de}-$ creased injection-related injury, ${ }^{6,34}$ improved access to healthcare, ${ }^{6}$ increased referrals for primary healthcare needs, reduced stigma, ${ }^{28}$ improved quality of life,, 34 and decreased risk of opioid overdose death. ${ }^{15,21}$

Despite the clear evidence in support of a harm reduction approach to managing the challenges presented when working with people who use substances, ${ }^{4,5,6,24,25}$ nurses might be reluctant to implement these practices within the care they provide to patients. ${ }^{10,14}$ This could be due to fear, blame, fragmentation of client care, the devaluation of addiction treatment, a lack of skills and education to provide care to this population, a lack of resources, or a pessimistic attitude towards client progress. ${ }^{44}$ Nurses require education on the evidence supporting harm reduction measures, ${ }^{14}$

J Mental Health Addic Nurs Vol 4(1):e14-e25; May 18, 2020.

This article is distributed under the terms of the Creative Commons Attribution-Non Commercial 4.0 International License. (c) Kerber et al. 
and we believe this should begin in undergraduate education to shift the healthcare culture away from the myths and stigmatizing beliefs that surround the concept of harm reduction and addiction. Strong public health leadership and advocacy will increase awareness of available programs and the important role these programs play in the addiction treatment care continuum. ${ }^{5,6}$

Given the benefit of a harm reduction approach, increasing the availability of supervised consumption sites, access to sterile injection supplies, and the opportunity to engage in medication-assisted treatment are important areas of healthcare services. With the creation of two injectable opiate clinics in 2018/2019, Alberta is well-positioned to engage in evaluation research which can provide evidence supporting the effectiveness of a harm reduction method of treatment. Well-proven evidence of harm reduction's effectiveness might create more opportunities for these clinics to be implemented across Canada. Political adversity can pose challenges to harm reduction implementation due to differing beliefs, values, and priorities. A government that does not value the importance of prioritization of harm reduction might halt new harm reduction projects while insisting a costly review be undertaken of existing harm reduction programs. ${ }^{45}$ Controversial social media posts regarding mental health and addictions can further the division between scientific evidence and value-laden judgements. ${ }^{46}$

The use of methamphetamine and other stimulants can cause short term tachycardia, increased blood pressure, temperature, and respiration, cardiac arrhythmias, violence, psychosis, and aggression. ${ }^{47}$ Chronic use can lead to stroke, permanent cognitive disability, and cardiac valve thickening. ${ }^{47}$ "Challenges exist in identifying effective interventions for those individuals injecting drugs other than opioids, particularly amphetamine-type stimulants and cocaine."5 These challenges are due to the unpredictable nature of amphetamines when used intravenously. Sterile supplies, education on the substance's effects, allowing the use of these substances in supervised consumption sites are important areas of focus when implementing harm reduction strategies. However, further research is needed to better understand how harm reduction can best be implemented with users of amphetamines. ${ }^{47}$
Specific research studies also need to be focused on harm reduction strategies that account for diversity (such as gender, age, and race) and inclusion strategies of these populations. ${ }^{34}$ Another important area of future research is harm reduction in rural communities. Telehealth and electronic resources are increasing availability to access, but there is still a large gap of services to remote areas and an increased risk of perceived stigma for people who are using substances. Nurses must be leaders and advocates for increased awareness, access, and education on harm reduction strategies and philosophy.

\section{CONCLUSION}

Concept analysis is important for the development of new knowledge and understanding of how clients experience various phenomena. ${ }^{7}$ As the concept of harm reduction continues to expand nurses require "the capacity to deal with dynamic and complex situations, lead innovation and carry foresight, [and] practice based on genuine respect with the [nurse] guiding, supporting, and travelling with patients through their illness." 48 Canada has an evolving and progressive approach to treating substance use, and therefore the concept of harm reduction can be confusing or not generally understood by nurses. As nurses are often the coordinators of care in their various roles, it is important to understand how harm reduction can be operationalized and implemented, as well as the benefits it provides to marginalized clients.

In this paper, we have presented an evolutionary analysis of the concept of harm reduction using the Rodgers method. Harm reduction, with the attributes of safety, supplies, education, partnerships, and policy, can be utilized by many disciplines in healthcare. Future research on the implementation of harm reduction strategies for people who use amphetamines, barriers to access in rural communities, and injectable opiate agonist treatment are necessary to continue the dialogue on harm reduction and decrease the stigma experienced by people who use substances.

\section{FUNDING}

The authors received no specific funding for this work.

J Mental Health Addic Nurs Vol 4(1):e14-e25; May 18, 2020.

This article is distributed under the terms of the Creative Commons Attribution-Non

Commercial 4.0 International License. (C) Kerber et al. 


\section{DISCLOSURE STATEMENT}

The authors report no conflict of interest.

\section{REFERENCES}

1. Government of Canada. Opioid-related harms and deaths in Canada. Ottawa: Author; 2019. https://www.canada. ca/en/health-canada/services/substance-use/problematicprescription-drug-use/opioids/data-surveillance-research/ harms-deaths.html

2. Canadian Institute for Health Information. Opioid-related harms in Canada Ottawa: Author; 2019. https://www .cihi.ca/sites/default/files/document/opioid-relatedharms-report-2018-en-web.pdf

3. Canadian Centre on Substance Abuse and Addiction. Hospital costs and impacts of substance use. Ottawa: Author; 2018. www.ccdus.ca/Eng/topics/Costs-ofSubstance-Abuse-in-Canada/Hospital-Costs-Impactsof-Substance-Use/Pages/default.aspx

4. Canadian Nurses Association. Harm reduction and substance use. Ottawa: Author; 2019. https://www. cna-aiic.ca/-/media/cna/page-content/pdf-en/joint_position_statement_harm_reduction_and_substance_use.pdf

5. Ball AL. HIV, injecting drug use and harm reduction: a public health response. Addiction 2007;102(5): 684-90.

6. Kulikowski J, Linder E. Making the case for harm reduction programs for injection drug users. Nurs 2018;48(6):46-51. doi:10.1097/01.NURSE.0000532745.80506.17

7. Rodgers BL. Concepts, analysis and the development of nursing knowledge: the evolutionary cycle. J of Advanced Nurs 1989;14(4):330-5. doi:10.1111/j.1365-2648.1989. tb03420.x

8. Morin KA, Eibl JK, Franklyn AM, et al. The opioid crisis: past, present and future policy climate in Ontario, Canada. Substance Abuse Treat Prev Policy 2017;12:1-7. doi:10.1186/s13011-017-0130-5

9. Bradbury-Jones C, Sambrook S, Irvine F. Power and empowerment in nursing: a fourth theoretical approach. J Advanced Nurs 2008;62(2):258-66. doi:10.1111/j.1365-2648.2008.04598.x

10. van Boekel LC, Brouwers EPM, van Weeghel J, et al. Stigma among health professionals towards patients with substance use disorders and its consequences for healthcare delivery: Systematic review. Drug Alcohol Depend 2013;131(1/2):23-35. doi:10.1016/ j.drugalcdep.2013.02.018
11. Manias E, Street A. Possibilities for critical social theory and Foucault's work: a toolbox approach. Nurs Inquiry 2000;7(1):50-60.

12. Kennedy-Hendricks A, Barry CL, Gollust SE, et al. Social stigma toward persons with prescription opioid use disorder: associations with public support for punitive and public health-oriented policies. Psychiatr Ser 2017;68(5):462-9. doi:10.1176/appi.ps.201600056

13. Sumner J. The nurse in the caring in nurse relationship: a critical social theory perspective. Int J Human Caring 2004;8(1):37-45.

14. Ford R. An analysis of nurses' views of harm reduction measures and other treatments for the problems associated with illicit drug use. Australian J of Adv Nurs 2010;28(1):14-24.

15. Estreet A, Archibald P, Tirmazi MT, et al. Exploring social work student education: The effect of a harm reduction curriculum on student knowledge and attitudes regarding opioid use disorders. Substance Abuse 2017;38(4):369-75. doi:10.1080/08897077.2017.1341447

16. James K, Samuels I, Moran P, et al. Harm reduction as a strategy for supporting people who self-harm on mental health wards: the views and experiences of practitioners. J Affect Dis 2017;214:67-73. doi:10.1016/j. jad.2017.03.002

17. McKeganey N. From harm reduction to drug user abstinence: a journey in drug treatment policy. J Substance Use 2011;16(3):179-94. doi:10.3109/1465989 1.2011 .580228

18. Barker KL, Galeota EY. Shining a LIGHT Into Drug Darkness. J Nurse Practitioners 2018;14(6):463-9. doi:10.1016/j.nurpra.2017.12.004

19. Bowles JM, Lankenau SE. "I gotta go with modern technology, so I'm gonna give "em the narcan": the diffusion of innovations and an opioid overdose prevention program. Qual Health Res 2019;29(3):345-56. doi:10.1177/1049732318800289

20. Bozinoff N, Small W, Long C, et al. Still "at risk": an examination of how street-involved young people understand, experience, and engage with "harm reduction" in Vancouver's inner city. Int J Drug Policy 2017;45:33-9. doi:10.1016/j.drugpo.2017.05.006

21. McDonald R, Campbell ND, Strang J. Twenty years of take-home naloxone for the prevention of overdose deaths from heroin and other opioids - conception and maturation. Drug Alcohol Depend 2017;178:176-87. doi:10.1016/j.drugalcdep.2017.05.001

J Mental Health Addic Nurs Vol 4(1):e14-e25; May 18, 2020.

This article is distributed under the terms of the Creative Commons Attribution-Non Commercial 4.0 International License. (C) Kerber et al. 
22. Deren S, Naegle M, Hagan H, et al. Continuing links between substance use and HIV highlight the importance of nursing roles. J Assoc Nurses AIDS Care 2017;28(4):622-32. doi:10.1016/j.jana.2017.03.005

23. Hilton BA, Thompson R, Moore-Dempsey L et al. Urban outpost nursing: the nature of the nurses' work in the AIDS Prevention Street Nurse Program. Public Health Nurs 2001;18(4):273-80.

24. Kerr T, Small W, Buchner C, et al. Syringe sharing and HIV incidence among injection drug users and increased access to sterile syringes. Am J Pub Health 2010;100(8):1449-53. doi:10.2105/AJPH.2009.178467

25. Kerr T, Tyndall MW, Lai C, et al. Drug-related overdoses within a medically supervised safer injection facility. Int J Drug Policy 2006;17(5):436-41.

26. Wallace B, Barber K, Pauly B. Sheltering risks: Implementation of harm reduction in homeless shelters during an overdose emergency. Int J Drug Policy 2018;83-9. doi:10.1016/j.drugpo.2017.12.011

27. Eversman M. Harm reduction practices in outpatient drug-free substance abuse settings. J Subst Use 2012;17(2):150-62. doi:10.3109/14659891.2010.540295

28. Goodyear K, Haass-Koffler CL, Chavanne D. Opioid use and stigma: The role of gender, language and precipitating events. Drug Alcohol Depend 2018;185:339-46. doi:10.1016/j.drugalcdep.2017.12.037

29. Mattick RP, Breen C, Kimber J, et al. Methadone maintenance therapy versus no opioid replacement therapy for opioid dependence. Cochrane Database Syst Rev 2009:1-34. doi:10.1002/14651858.CD002209

30. Health Canada. Harm Reduction: Canadian Drugs and Substances Strategy. Ottawa: Author; 2019. https://www. canada.ca/en/health-canada/services/substance-use/ canadian-drugs-substances-strategy/harm-reduction. html\#a

31. Fischer B, Rehm J, Tyndall M. Effective Canadian policy to reduce harms from prescription opioids: learning from past failures. Can Med Assoc J 2016;188(17-18):1240-4. doi:10.1503/cmaj.160356

32. Health Canada. About the Good Samaritan Drug Overdose Act. Ottawa: Author; 2019. Available at: https://www .canada.ca/en/health-canada/services/substance-use/ problematic-prescription-drug-use/opioids/about-good -samaritan-drug-overdose-act.html

33. Canadian Institutes of Health Research. Canadian research initiative in substance misuse (CRISM) Ottawa:
Author; 2019. Available at: http://www.cihr-irsc. gc.ca/e/44597.html

34. Pauly BB, Reist D, Belle-Isle L, et al. Housing and harm reduction: What is the role of harm reduction in addressing homelessness? Int J Drug Policy 2013;24(4):284-90. doi:10.1016/j.drugpo.2013.03.008

35. Fagerström KO, Bridgman K. Tobacco harm reduction: The need for new products that can compete with cigarettes. Addict Behav 2014;39(3):507-11. doi:10.1016/j. addbeh.2013.11.002

36. Souleymanov R, Allman D. Articulating connections between the harm-reduction paradigm and the marginalisation of people who use illicit drugs. Br J Social Work 2016;46(5):1429-45. doi:10.1093/bjsw/ bcv067

37. Aceijas C. The ethics in substitution treatment and harm reduction. an analytical review. Pub Health Rev 2012;34(1):1-12. doi:10.1007/BF03391668

38. Timko C, Schultz NR, Cucciare MA, et al. Retention in medication-assisted treatment for opiate dependence: A systematic review. J Addict Dis 2016;35(1):22-35. doi:10.1080/10550887.2016.1100960

39. Merriam-Webster. Definition of PRAGMATISM. Author: 2019. Available at: https://www.merriam-webster.com/ dictionary/pragmatism

40. Metrebian N, Groshkova T, Hellier J, et al. Drug use, health and social outcomes of hard-to-treat heroin addicts receiving supervised injectable opiate treatment: secondary outcomes from the Randomized Injectable Opioid Treatment Trial (RIOTT). Addiction 2015;110(3):479-90. doi:10.1111/add.12748

41. BC Centre on Substance Use. Guidance for injectable opioid agonist treatment for opioid use disorder. Vancouver: Author; 2019. Available at: http://www. bccsu.ca/wp-content/uploads/2017/10/BC-iOATGuidelines-10.2017.pdf

42. Palis H, Marchand K, Guh D, et al. Men's and women's response to treatment and perceptions of outcomes in a randomized controlled trial of injectable opioid assisted treatment for severe opioid use disorder. Subst Abuse Treat Prevent Policy 2017;12:1-12. doi:10.1186/ s13011-017-0110-9

43. Bell J, Belackova V, Lintzeris N. Supervised injectable opioid treatment for the management of opioid dependence. Drugs 2018;78(13):1339-52. doi:10.1007/ s40265-018-0962-y

J Mental Health Addic Nurs Vol 4(1):e14-e25; May 18, 2020.

This article is distributed under the terms of the Creative Commons Attribution-Non

Commercial 4.0 International License. (c) Kerber et al. 
44. Ross, C. A., Goldner, E. M. Stigma, negative attitudes and discrimination towards mental illness within the nursing profession: A review of the literature. J Psychiatr Mental Health Nursing 2009;16(6):558-567. doi:10.1111/j.1365-2850.2009.01399.x

45. Canadian Broadcasting Corporation. My son no longer has a voice: Overdose victims' relatives urge UCP to fund more consumption sites. (2019, June 7). Retrieved from https://www.cbc.ca/

46. Bell D. (2019, July 17). Deleted tweet about big pharma by associate minister for addictions 'laughably absurd,' says scientist. Canadian Broadcast Corporation. Retrieved from https://www.cbc.ca/

47. Cannon E. How to address methamphetamine abuse in the United States: nurses leading comprehensive care. MEDSURG Nurs 2018;27(2):103-7.

48. Gray A. Advanced or advancing nursing practice: what is the future direction for nursing? British $\mathrm{J}$ of Nurs 2016;25(1):8-13. doi:10.12968/bjon.2016.25.1.8 